\title{
Late Gastropleural Fistula Following Bariatric Surgery: Case Report
}

\author{
Barbi GM ${ }^{1}$, Pará $\mathrm{LEG}^{1}$, Lopes FAD ${ }^{2}$, Okawa $\mathrm{L}^{3}$, Yamaguchi GY ${ }^{3}$, Grava $\mathrm{S}^{4^{*}}$ \\ ${ }^{1}$ Medicine Student, UniCesumar Medical School, Avenida Guedner, Maringá, Brazil \\ ${ }^{2}$ Thoracic Surgeon, Hospital Paraná, Maringá, Brazil \\ ${ }^{3}$ Gastric Surgeons, Digestive Endoscopy, Hospital Paraná, Maringá, Brazil \\ ${ }^{4}$ Pneumologist, MD. Msc., Professor of Medicine, UniCesumar Medical School, Avenida Guedner, Maringá, Brazil
}

Corresponding Author: Sergio Grava, MD, Msc ${ }^{\text {ORCID iD }}$

Address: Pneumologist, Professor of Medicine, UniCesumar Medical School, Avenida Guedner, 1610, 87050-900, Maringá, Brazil.

Received date: 08 December 2020; Accepted date: 11 January 2021; Published date: 19 January 2021

Citation: Barbi GM, Pará LEG, Lopes FAD, Okawa L, Yamaguchi GY, Grava S. Late Gastropleural Fistula Following Bariatric Surgery: Case Report. Asp Biomed Clin Case Rep. 2021 Jan 19;4(1):30-37.

Copyright (C) 2021 Barbi GM, Pará LEG, Lopes FAD, Okawa L, Yamaguchi GY, Grava S. This is an open-access article distributed under the Creative Commons Attribution License, which permits unrestricted use, distribution, and reproduction in any medium provided the original work is properly cited.

\begin{abstract}
Although bariatric surgery procedures represent well-established methods for sustained weight loss worldwide, an important number of postoperative complications can be expected in both restrictive and mixed procedures. Gastropleural fistulas (GPF) represent an extremely rare life-threatening complication following bariatric surgery. Defined as a pathological communication between the gastric tract and the pleural cavity, the establishment of an appropriate and timely diagnosis may be quite challenging for physicians. We report on a case of a 33-year-old woman, who underwent a bariatric sleeve procedure, who presented several episodes of pneumonia in different occasions postoperatively with undiagnosed causes. Three years postoperatively the patient was hospitalized for a more detailed investigation and underwent video segmentectomy unsuccessfully. GPF was diagnosed following the observation of nutritional supplement escaping through the chest drain. The patient was initially treated with different endoscopic techniques (argon glow plasma, and endoscopic balloon dilatation) for the closure of the GPF, but despite all attempts, she eventually progressed to total gastrectomy. Bariatric surgery patients suffering from recurrent episodes of pneumonia should raise the alert for the possibility of GPF.
\end{abstract}

\section{Keywords}

Case Report, Gastropleural Fistula, Gastrectomy, Pneumonia, Gastric Fistula

\section{Introduction}

The first gastric by-pass with a single loop anastomosis was performed by Edward Mason in the 1960s [1]. Since then, new techniques have been introduced, improving and consolidating the procedure as one of the most effective methods in the management of severe obesity [2-4]. According to the American Society of Metabolic and Bariatric Surgery, the number of procedures increased by around 10\%, from 196,000 to 216,000, between 2015 and 2016 in the USA alone [5]. Currently, the most common techniques for bariatric surgeries are sleeve gastrectomy, gastric by-pass (Y-en-Roux), adjustable gastric band, and duodenal switch. While sleeve gastrectomy is the most commonly performed bariatric procedure in the USA, gastric by-pass is favored by other countries $[5,6]$.

Despite improvements in bariatric surgery, early and long-term postoperative complications as well as nutritional disorders are expected events $[7,8]$. Although death rarely occurs, potentially serious 
Citation: Barbi GM, Pará LEG, Lopes FAD, Okawa L, Yamaguchi GY, Grava S. Late Gastropleural Fistula Following Bariatric Surgery: Case Report. Asp Biomed Clin Case Rep. 2021 Jan 19;4(1):30-37.

Case Report

respiratory complications caused by bariatric surgery deserves the close attention of physicians [9]. A rare and potentially life-threatening complication of the respiratory and gastric anatomy is the formation of a gastropleural fistula (GPF). Initially described by Markowitz and Herter [10] in the 196os, the GPF is an anomalous communication between the operated stomach and the pleural cavity. GPF development time may vary greatly, between 2 months up to 13 years, and can result in important recurrent pulmonary infections, abscesses, and even septic shock [11].

Considering that very few cases of GPF following bariatric surgery have been reported in the literature, this case report describes the clinical presentation and endoscopic findings of a GPF of difficult resolution three years following sleeve gastrectomy.

\section{Patient Information}

A 33-year-old brazilian female patient presented to our service in march 2017 complaining of recurrent bouts of pneumonia for most of the previous three years, always associated with productive cough and purulent secretion, chest pain, dyspnea, and temperature. In January 2014, the patient underwent a vertical sleeve gastrectomy for the management of severe obesity. She had no previous history of smoking, drinking, or any other pathological conditions. No information on family diseases were available.

\section{Clinical Findings}

Eleven months postoperatively, she was diagnosed with pneumonia, which became the first of a series of episodes over the next three years, always affecting the posterior segment of the left lower lobe (LLL). Different types of antibiotics either in isolation (levofloxacin, moxifloxacin, meropenem), or in combination (amoxicillin/ clavulanate, and ceftriaxone/azithromycin) were used for the treatment of each individual episode.

When she arrived at our service, physical examination showed normal blood pressure (120/80 $\mathrm{mmHg}$ ) and normal breath rate, auscultation with positive breath sounds bilateral, and the presence of fine crackles at the base of the left lung. Oxygen saturation by pulse oximetry was $96 \%$ on room air. Pulmonary function assessment, laboratory tests, and a CT scan were requested. Spirometry results showed normal lung function, while laboratory tests only showed altered haemoglobin values (Table-1, Table-2, and Fig-1), and a CT scan revealed the presence of consolidation in the left lower lobe with surrounding ground-glass opacity (Fig-1). The patient was initially treated with ciprofloxacin.

Table-2: Laboratory Results upon Admission

\begin{tabular}{|l|c|}
\hline \multicolumn{1}{|c|}{ Laboratory test } & Results \\
\hline GAMMA GLOBULIN & $1.08 \mathrm{~g} / \mathrm{dl}$ \\
\hline ALBUMIN & $51 \mathrm{~g} / \mathrm{dl}$ \\
\hline IMMUNOGLOBULIN A & $303 \mathrm{~g} / \mathrm{L}$ \\
\hline IMMUNOGLOBULIN M & $144 \mathrm{~g} / \mathrm{L}$ \\
\hline IMMUNOGLOBULIN G & $1223 \mathrm{~g} / \mathrm{L}$ \\
\hline $\begin{array}{l}\text { ASPARTATE } \\
\text { AMINOTRASNFERASE (AST) }\end{array}$ & $10 \mathrm{U} / \mathrm{L}$ \\
\hline $\begin{array}{l}\text { ALANINE AMINOTRANSFERASE } \\
\text { (ALT) }\end{array}$ & $22 \mathrm{U} / \mathrm{L}$ \\
\hline CREATININE & $0.6 \mathrm{mg} / \mathrm{dL}$ \\
\hline HAEMOGLOBIN & $8.8 \mathrm{~g} / \mathrm{dL}$ \\
\hline LEUCOCYTES & $4700 \mathrm{cells} / \mu \mathrm{L}$ \\
\hline LYMPHOCYTES & $43 \%$ \\
\hline SEGMENTED & $48 \%$ \\
\hline ANTINUCLEAR FACTOR & Absent \\
\hline RHEUMATOID FACTOR & Negative \\
\hline ANCA P & Negative \\
\hline ANCA C & Negative \\
\hline
\end{tabular}

\begin{tabular}{|l|c|c|c|c|}
\hline \multicolumn{1}{|c|}{ Expiratory } & Real & Predicted & \% Predicted & Result \\
\hline FVC & $2.08 \mathrm{~L}$ & $3.40 \mathrm{~L}$ & $61.03 \%$ & $2.85 \mathrm{~L}$ \\
\hline FEV1 & $1.92 \mathrm{~L}$ & $2.91 \mathrm{~L}$ & $65.81 \%$ & $2.48 \mathrm{~L}$ \\
\hline FEV1/FCV & $92.26 \%$ & $85.06 \%$ & $108.47 \%$ & $77.01 \%$ \\
\hline PEF & $4.03 \mathrm{~L} / \mathrm{S}$ & N/A & N/A & N/A \\
\hline
\end{tabular}

FVC - Forced Vital Capacity; FEV1 - Forced Expiratory Volume in 1 Second; FEV1/FVC - Ratio of FEV1 to FVC; PEF Peak Expiratory Flow; FEF25-75\% - Forced Expiratory Flow 25-75\%. 
Citation: Barbi GM, Pará LEG, Lopes FAD, Okawa L, Yamaguchi GY, Grava S. Late Gastropleural Fistula Following Bariatric Surgery: Case Report. Asp Biomed Clin Case Rep. 2021 Jan 19;4(1):30-37.

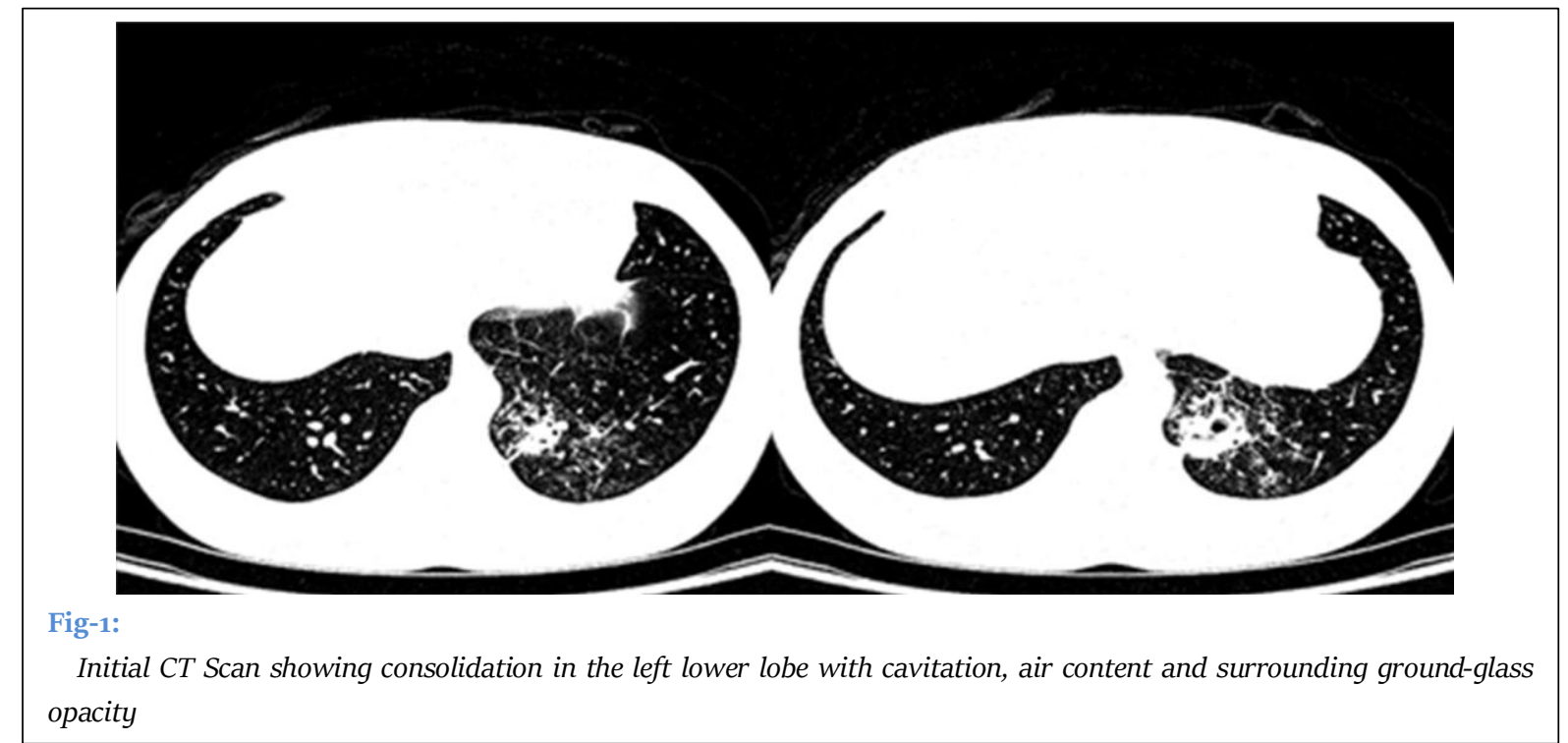

\section{Diagnostic Assessment}

In April 2018, the patient returned with a new episode of pneumonia, when she received a combination of azithromycin/ceftriaxone, and later cefuroxime. Because none of the treatments improved her condition, the patient was admitted to the hospital for a more detailed investigation of the case. Bronchofibroscopy with transbronchial biopsy and bronchoalveolar lavage collection showed a nonspecific inflammatory reaction. Additionally, culture tests showed no pathogen growth. Acid-alcohol resistant bacilli (AARB) and fungi screening were also negative. A few days later, the patient underwent video segmentectomy in the LLL for the excision of the infectious lesion. Culture tests again showed no bacterial or fungal growth, and the anatomopathological examination showed a foreign body-type inflammatory reaction. A series of different antibiotics were administered without effect.

Four days after video segmentectomy, a CT scan showed empyema and consolidation in the LLL with air bronchogram (Fig-2). Eleven days postoperatively, a new CT scan showed a small regression of the condition but no resolution (Fig-3). At that time, nutritional supplement was observed escaping through the chest drain, suggesting the presence of a fistulous communication between the stomach and the pleural cavity, which was confirmed with the methylene blue test (Fig-4). Upper digestive endoscopy (UDE) confirmed the presence of a fistula in the proximal gastric stump region, close to the angle of Hiss, as well as the narrowing of the lumen at the angular notch (Fig-5a). Esophagogastroduodenoscopy confirmed the diagnosis of fistula with the escape of contrast to the pleural cavity.

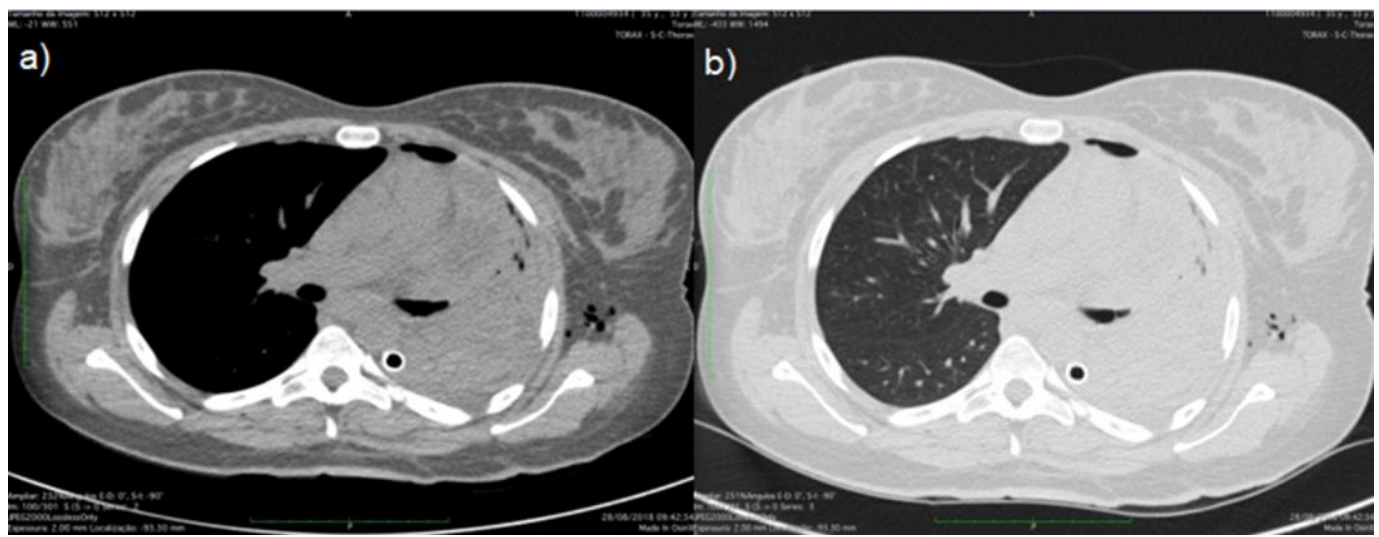

Fig-2:

CT Scan 4 days following videosegmentectomy. The opacities seen in the left lower lobe confirmed the persistence of the infection. a) Mediastinal window; b) Lung window 
Citation: Barbi GM, Pará LEG, Lopes FAD, Okawa L, Yamaguchi GY, Grava S. Late Gastropleural Fistula Following Bariatric Surgery: Case Report. Asp Biomed Clin Case Rep. 2021 Jan 19;4(1):30-37.

\section{Case Report}

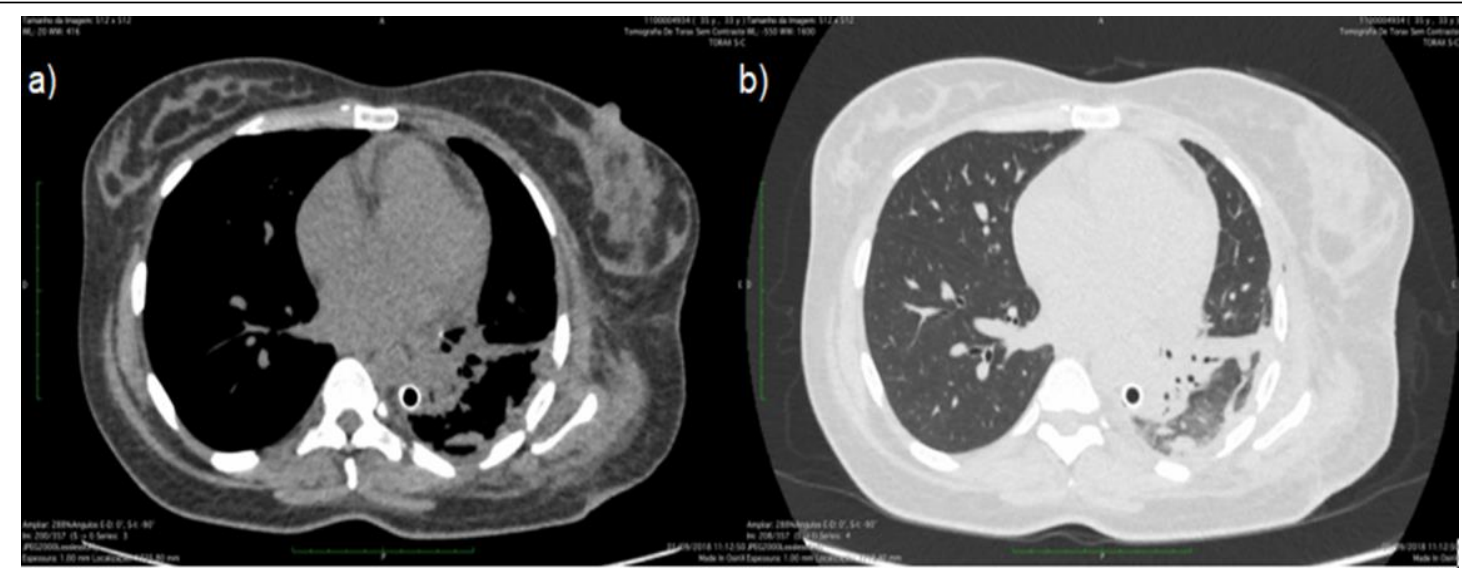

Fig-3:

CT Scan 11 days following videosegmentectomy showing the persistence of the infection. a) Mediastinal window; b) Lung window

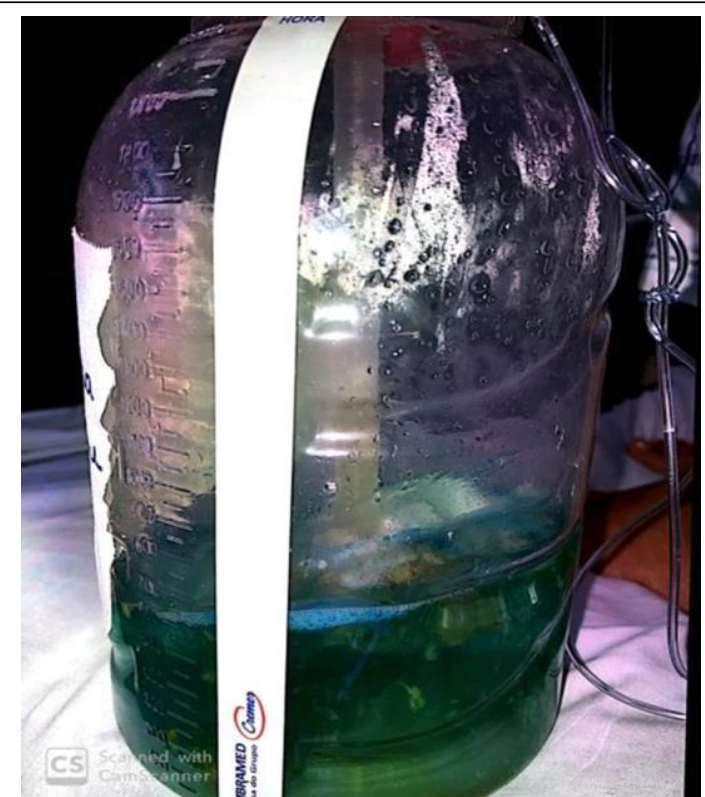

Fig-4:

Thorax water seal drainage from the chest positive for Methylene Blue ingestion test

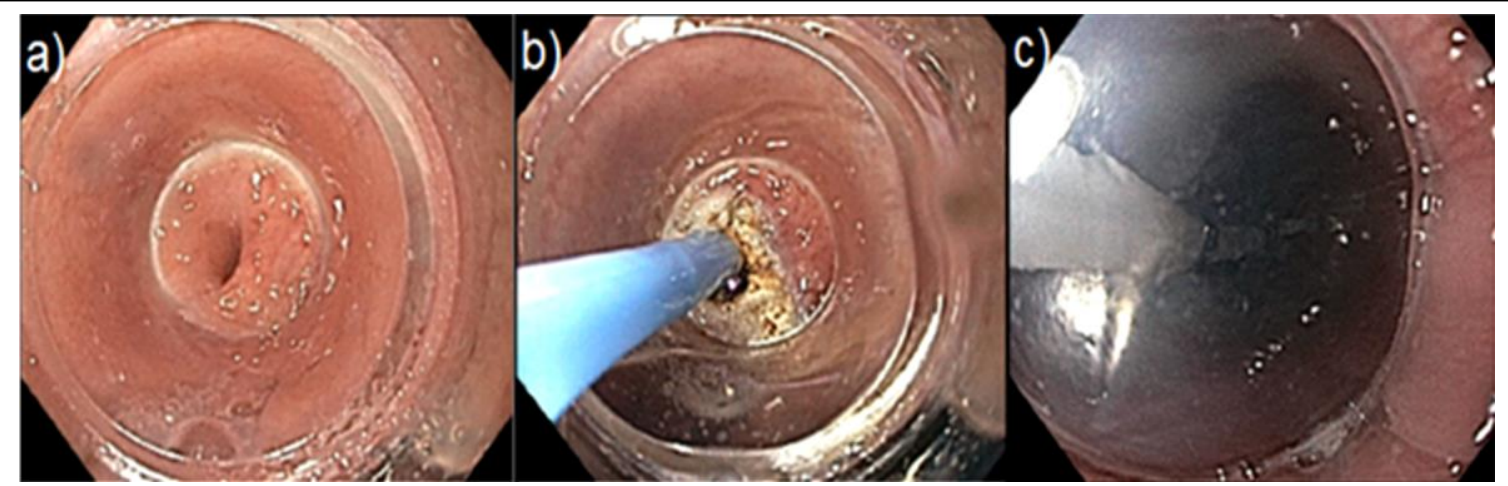

Fig-5:

Upper Digestive Endoscopy: a) Visualization of the internal fistulous orifice close to the angle of Hiss; b) Argon glow plasma; c) Teflon-guided guidewire in gastric position for serial endoscopic balloon dilation (30 $\mathrm{mm}$ ) of the stomach hourglass. 
Citation: Barbi GM, Pará LEG, Lopes FAD, Okawa L, Yamaguchi GY, Grava S. Late Gastropleural Fistula Following Bariatric Surgery: Case Report. Asp Biomed Clin Case Rep. 2021 Jan 19;4(1):30-37.

\section{Case Report}

\section{Therapeutic Intervention}

Multiple attempts at endoscopic closure of the GPF with argon glow plasma performed (Fig-5b), as well as serial endoscopic balloon dilation (Rigiflex ${ }^{\circledR}$ ) of the stomach hourglass (Fig-5c). Despite all attempts, no definitive resolution of the fistula was attained (Fig-6), and the patient progressed to total gastrectomy in February 2019.

\section{Timeline}

Fig-7 illustrates the timeline of the main events as well the treatments and procedures performed from the moment the patient underwent bariatric surgery until GPF closure. In the timeline, it is possible to observe a considerable number of different antibiotics used throughout the period.

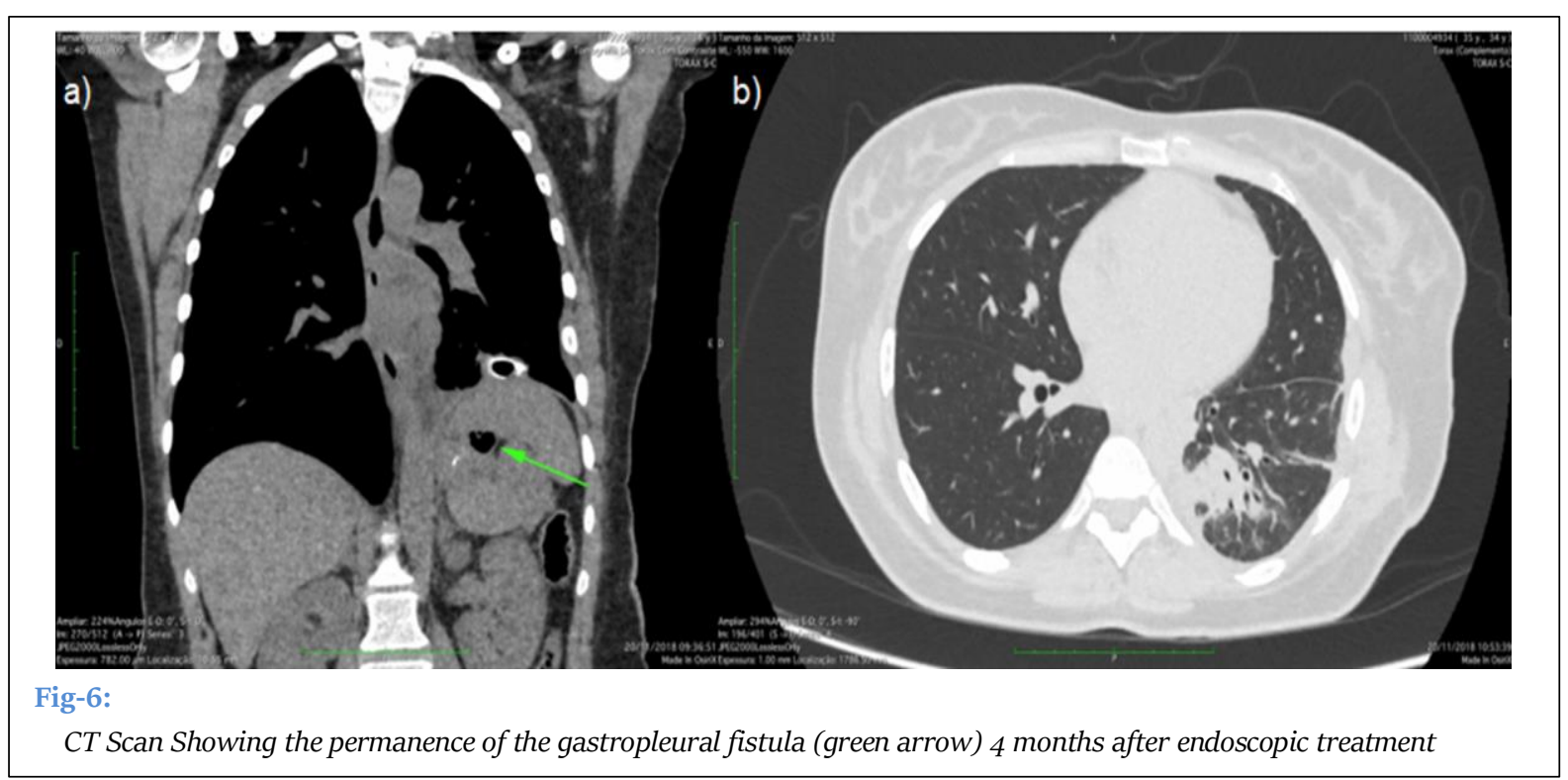

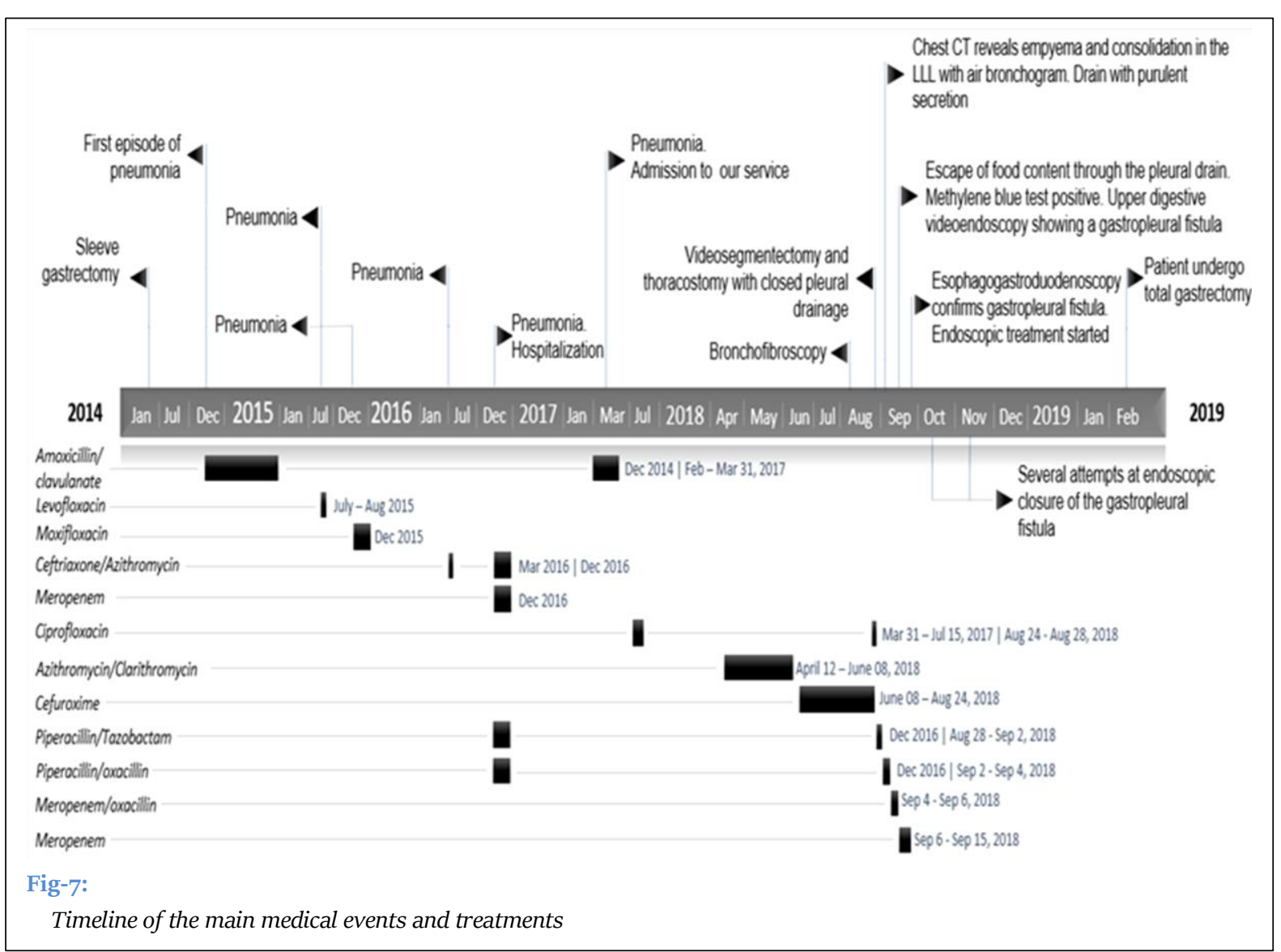




\section{Follow-up and Outcomes}

Postoperative follow-up has been favorable, with complete resolution of the episodes of recurrent pneumonia, and the patient is progressing satisfactorily without further complaints of infectious conditions.

\section{Discussion}

Bariatric surgery is increasingly performed worldwide [12] and continues growing as an effective and well-established method for sustained weight loss and remission of many metabolic comorbidities. However, early and late postoperative complications are expected depending on the surgical technique, which can be classified into restrictive and mixed procedures $[13,14]$.

By definition, a gastropleural fistula (GPF) is an abnormal and pathological communication involving the stomach and the pleural cavity. Although the precise mechanism for its formation has not been completely elucidated, their development has been related to post-surgical leaks, which promote the formation of abscesses responsible for the structural elaboration of the fistulous tract. Until a communication between the gastric tract and the pleural cavity is complete, the time required for fistula formation and the emergence of the first symptoms may vary considerably, ranging from a period of two months up to thirteen years [11]. The clinical presentation is often insidious, and the main symptoms include temperature and dyspnea [15], productive cough and recurrent pneumonia [11]; chest pain and dry cough [16]; abdominal pain [17], and septic shock [18]. The suspicion, identification, and treatment of GPF is crucial to avoid serious complications for the patient.

In addition to bariatric surgery [19], other etiologies such as trauma [20], malignancy [21,22], diaphragmatic herniation of the stomach [23], and hiatus hernia [10] have been reported as possible causes for GPFs. The diagnosis of GPFs is not always straightforward and requires imaging resources and detailed analysis of the patient's medical history $[13,14]$. Besides information on the bariatric surgery technique employed, it is also important to know when the first signs of respiratory infection emerged [11], and the treatment employed. In the present case, 11 months were required for the establishment of effective communication between the gastric and pleural cavities, and for the first episode of pneumonia. From then on, the patient suffered from recurring episodes of pneumonia, which was conventionally treated with different kinds of broad-spectrum antibiotics for approximately three years, with unsatisfactory results. When she was eventually hospitalized for a more careful investigation, CT Scans showed the presence of infection in the LLL. Videosegmentectomy was then performed in an attempt to completely excise the lesion, which reduced in the signs of infection, but was ineffective to completely resolve them.

The suspicion of a GPF occurred by chance, through the observation of nutritional fluids in the pleural drainage, confirmed by the methylene blue, which justified further investigation with UDE. The combination of chest tomography and UDE is considered a sensitive method for the diagnosis of GPF [17]. UDE is fundamental to determine the location and exact dimensions of the fistulous orifice, and can also be used to clot the fistula with argon glow plasma [24], implantation of enteric stents [17], excision of the fistula with diaphragmatic repair [16], and the implantation of vicryl screens with fibrin glue.

Only a few cases have already reported on the treatment of a GPF following bariatric surgery. AlShurafa [16], reported the case of a patient diagnosed with GPF two years after undergoing gastric by-pass, which was excised with diaphragmatic repair and decortication of affected pleura. In another report, Ghanem [17] chose to insert an enteric stent to cover the fistulous opening in a 43-year-old patient who had undergone gastric by-pass six months earlier, obtaining satisfactory results. However, endoscopic treatment, either by clipping the fistula, using argon plasma coagulation [24], or stents $[17,25]$, have not always been shown to be effective, in which case more invasive techniques for the definitive resolution of the fistula, either through gastrectomy or thoracotomy, have to be considered. This was the case in the present report, in which the use of argon glow plasma was unsuccessful. Because the fistula was treated more than four years after bariatric surgery, its size was 
probably the reason for the failure, and the need to conduct a gastrectomy.

Although the patient is progressing satisfactorily without further complaints of infectious conditions, much suffering and inconvenience could have been avoided by the early diagnosis of GPF. However, because the gastric and the respiratory systems are two separate entities, a connection between them is not an expected occurrence. Moreover, fistula formation and communication between the two cavities may take several months or even years. To make matters worse, pneumonia is a secondary condition to several other primary conditions, which can misdirect physicians' attention elsewhere. Thus, the time span between different medical events can often affect diagnosis and treatment without achieving a definitive resolution of the case.

Therefore, this case reinforces the need for general physicians and respiratory specialists to be made aware of this serious condition. Bariatric surgery patients suffering from recurrent episodes of pneumonia should raise the alert for the possibility of GPF. Despite its rarity, GPF should be included in the list of possible complications following sleeve gastrectomy and gastric by-pass.

\section{Data Availability}

No data were used to support this study.

\section{Conflict of Interests}

All authors have read and approved the final version of the manuscript. The authors have no conflicts of interest to declare.

\section{Funding Statement}

This work did receive any specific funding. It was performed as part of the requirements for the conclusion of the Medical Course at UniCesumar, Maringá, Brazil.

\section{Acknowledgments}

The author would like to express their gratitude to Mr. Antonio Carlos Correa for his assistance with the English version of the manuscript.

\section{References}

[1] Mason EE, Ito C. Gastric bypass in obesity. Surg Clin North Am. 1967 Dec;47(6):1345-51. [PMID: 6073761]

[2] Gastrointestinal surgery for severe obesity: National Institutes of Health Consensus Development Conference Statement. Am J Clin Nutr. 1992 Feb;55(2 Suppl):615S-9S. [PMID: 1733140]

[3] Rubino F, Nathan DM, Eckel RH, Schauer PR, Alberti KG, Zimmet PZ, Del Prato S, Ji L, Sadikot SM, Herman WH, Amiel SA, Kaplan LM, TaroncherOldenburg G, Cummings DE; Delegates of the 2nd Diabetes Surgery Summit. Metabolic Surgery in the Treatment Algorithm for Type 2 Diabetes: A Joint Statement by International Diabetes Organizations. Diabetes Care. 2016 Jun;39(6):861-77. [PMID: 27222544]

[4] Centre for Public Health Excellence at NICE (UK); National Collaborating Centre for Primary Care (UK). Obesity: The Prevention, Identification, Assessment and Management of Overweight and Obesity in Adults and Children. London: National Institute for Health and Clinical Excellence (UK); 2006.

[5] English WJ, DeMaria EJ, Brethauer SA, Mattar SG, Rosenthal RJ, Morton JM. American Society for Metabolic and Bariatric Surgery estimation of metabolic and bariatric procedures performed in the United States in 2016. Surg Obes Relat Dis. 2018 Mar;14(3):259-63. [PMID: 29370995]

[6] Nguyen NT, Varela JE. Bariatric surgery for obesity and metabolic disorders: state of the art. Nat Rev Gastroenterol Hepatol. 2017 Mar;14(3):16o-69. [PMID: 27899816]

[7] van der Beek ES, Monpellier VM, Eland I, Tromp E, van Ramshorst B. Nutritional deficiencies in gastric bypass patients; incidence, time of occurrence and implications for post-operative surveillance. Obes Surg. 2015 May;25(5):818-23. [PMID: 25330868]

[8] Ma IT, Madura JA 2nd. Gastrointestinal Complications after Bariatric Surgery. Gastroenterol Hepatol (N Y). 2015 Aug;11(8):526-35. [PMID: 27118949]

[9] Morino M, Toppino M, Forestieri P, Angrisani L, Allaix ME, Scopinaro N. Mortality after bariatric surgery: analysis of 13,871 morbidly obese patients from a national registry. Ann Surg. 2007 Dec;246(6):1002-1007; discussion 1007-1009. [PMID: 18043102] 
Citation: Barbi GM, Pará LEG, Lopes FAD, Okawa L, Yamaguchi GY, Grava S. Late Gastropleural Fistula Following Bariatric Surgery: Case Report. Asp Biomed Clin Case Rep. 2021 Jan 19;4(1):30-37.

Case Report

[10] Markowitz AM, Herter FP. Gastro-pleural fistula as a complication of esophageal hiatal hernia. Ann Surg. 196o Jul;152(1):129-34. [PMID: 14421290]

[11] Alghanim F, Alkhaibary A, Alzakari A, AlRumaih A. Gastropleural Fistula as a Rare Complication of Gastric Sleeve Surgery: A Case Report and Comprehensive Literature Review. Case Rep Surg. 2018 Dec 20;2018:2416915. [PMID: 30671274]

[12] Angrisani L, Santonicola A, Iovino P, Formisano G, Buchwald H, Scopinaro N. Bariatric Surgery Worldwide 2013. Obes Surg. 2015 Oct;25(10):1822-32. [PMID: 25835983]

[13] Schulman AR, Thompson CC. Complications of Bariatric Surgery: What You Can Expect to See in Your GI Practice. Am J Gastroenterol. 2017 Nov;112(11):1640-55. [PMID: 28809386]

[14] Contival N, Menahem B, Gautier T, Le Roux Y, Alves A. Guiding the non-bariatric surgeon through complications of bariatric surgery. J Visc Surg. 2018 Feb;155(1):27-40. [PMID: 29277390]

[15] Jiramethee N, Mira-Avendano I, Phelan J. An unusual case of gastro-pleural fistula masquerading as pneumonia following bariatric surgery. $\mathrm{C}_{52}$. Critical Care Case Reports: Unusual GI Causes of Critical Illness. 2017; A5807-A5807.

[16] Al-Shurafa H, Alghamdi S, Albenmousa A, Alolayan H, Al-Shurafa Z. Gastropleural fistula after single anastomosis gastric bypass. A case report and review of the literature. Int $\mathrm{J}$ Surg Case Rep. 2017;35:82-86. [PMID: 28458144]

[17] Ghanem OM, Abu Dayyeh BK, Kellogg TA. Management of Gastropleural Fistula after Revisional Bariatric Surgery: A Hybrid Laparoendoscopic Approach. Obes Surg. 2017 Oct;27(10):2773-77. [PMID: 28785977]
[18] Andrawes S, El Douaihy Y. Using the endoscopic overstitching device and fully covered esophageal stents for closure of a gastropleural fistula and repair of a deformed gastric sleeve. VideoGIE. 2017 May 4;2(5):98-99. [PMID: 29905278]

[19] Nguyen D, Dip F, Hendricks L, Lo Menzo E, Szomstein S, Rosenthal R. The Surgical Management of Complex Fistulas After Sleeve Gastrectomy. Obes Surg. 2016 Feb;26(2):245-50. [PMID: 26224371]

[20] Chowdary PB, Sadashivaiah SB, Gangappa RB, Shivashankar SC. Gastro pleural fistula: a rare entity presenting as a complication of empyema thoracis following stab injury to the chest. J Clin Diagn Res. 2015 Apr;9(4):PDo5-Do6. [PMID: 26023592]

[21] Bozkurt MA, Köneş O, Başoğlu I, Alış H. Gastropleural fistula: a rare complication of ewing sarcoma. Korean J Thorac Cardiovasc Surg. 2013 Aug;46(4):293-94. [PMID: 24003412]

[22] Neri A, Lambert Y, Marrelli D, Di Mare G, Mastrogiacomo D, Corso G, Volterrani L, Roviello F. Gastro-pleuro-pericardial fistula following combined radiation and chemotherapy for lung metastases from renal cell carcinoma: report of a case. Surg Today. 2013 Dec;43(12):1457-6o. [PMID: 23307297]

[23] Tzeng JJ, Lai KH, Lo GH, Hsu JH, Mok KT. Gastropleural fistula caused by incarcerated diaphragmatic herniation of the stomach. Gastrointest Endosc. 2001 Mar;53(3):382-84. [PMID: 11231411]

[24] Mendoza Ladd A, Al-Bayati I, Shah P, Haber G. Endoscopic closure of a gastropleural fistula. Endoscopy. 2015;47 Suppl 1 UCTN:E131-32. [PMID: 25857475]

[25] Marr B, Neddleman B, Mikami D. Endoscopic stenting for treatment of leaks following sleeve gastrectomy. World Journal of Laparoscopic Surgery. 2012;5(3):139-42. 